\title{
AN EXPLICIT REPRESENTATION AS QUASI-SUM OF SQUARES OF A POLYNOMIAL GENERATED BY THE AG INEQUALITY
}

\author{
T. V. TARARYKOVA
}

Abstract. An explicit representation of the difference $\left(x_{1}+\cdots+x_{n}\right)^{n}-n^{n} x_{1} \cdots x_{n}$ for all natural $n \geqslant 2$ is given as a sum of $p_{i j}\left(x_{i}-x_{j}\right)^{2}$ over all $1 \leqslant i<j \leqslant n$ where $p_{i j}=p_{i j}\left(x_{1}, \ldots, x_{n}\right)$ are homogeneous polynomials of degree $n-2$ whose coefficients at all possible monomials of degree $n-2$ are positive.

Mathematics subject classification (2000): 26D05, 11P81, 05E05.

Key words and phrases: arithmetic-geometric (AG) inequality, quasi-sum of squares.

\section{REFERENCES}

[1] P. S. BulLEN, Handbook of Means and Their Inequalities, Kluwer, Dordrecht-Boston-London, 2003.

[2] I. Gusić, A purely algebraic proof of AG inequality, Mathematical Inequalities and Applications, 8, (2) (2005), 191-198.

[3] A. HuRWITZ, Über den Vergleich des arithmetischen und des geometrischen Mittels, J. Reine Angew. Math., 108, (1891), 266-268. See also: Math. Werke, Basel, 1933, 505-507. 